\title{
EVALUASI PENGENDALIAN MUTU PADA PROYEK PEMBANGUNAN OBYEK WISATA SEDUDO DI KABUPATEN NGANJUK
}

\author{
${ }^{1 *}$ Hari Prasetiawan, ${ }^{2}$ Ahmad Ridwan, ${ }^{3}$ Yosef Cahyo S.P. \\ Fakultas Teknik Universitas Kadiri, \\ email: ${ }^{1 *}$ hariprasetiawan12@gmail.com, ${ }^{2}$ ahmad ridwan@unik-kediri.ac.id, ${ }^{3}$ yosef.cs@unik- \\ kediri.ac.id
}

\begin{abstract}
The supervisory consultant is one of the parties that play a very important role in quality control in construction work. The purpose of this study is to evaluate the performance and role of the supervisory consultant in controlling quality in construction work based on the results of the analysis and observations of weekly and monthly reports made by the supervisory consultant. The data analysis method used in this study is qualitative with comparative and implementation techniques, namely comparing the supervisory consultant's monthly report with Minister of Public Works Regulation No. $06 /$ PRT / M / 20082008 and Guidebook for Procedure for Reporting the Results of Building Supervision, Module - 5 Department of Public Works. The results of the analysis showed that the performance of the supervisory consultant was not optimal in terms of quality control because the supervisory consultant did not follow the reference or method in accordance with existing regulations. Factors less than optimal performance of consultants are influenced by various factors such as lack of labor, unfavorable weather so that it cannot be done overtime until night and the provision of material experiences extinction.
\end{abstract}

Keywords : : Project Quality Control, Role Of Supervisory Consultant, Quality Assurance (QA), Construction Work

\begin{abstract}
ABSTRAK
Konsultan pengawas merupakan salah satu pihak yang sangat berperan pada pengendalian mutu dalam pekerjaan konstruksi. Tujuan dari penelitian ini adalah untuk mengevaluasi dari kinerja dan peranan konsultan pengawas dalam mengendalikan mutu pada pekerjaan konstruksi berdasarkan dari hasil analisa dan pengamatan laporan mingguan dan bulanan yang dibuat oleh konsultan pengawas. Metode analisis data yang digunakan dalam penelitian ini secara kualitatif dengan teknik komparasi dan implementasi yaitu membandingkan laporan bulanan konsultan pengawas dengan Peraturan Menteri Pekerjaan Umum No. 06/PRT/M/2008 tahun 2008 dan Buku panduan Tata cara Pelaporan Hasil Pengawasan Bangunan Gedung, Modul - 5 Departemen Pekerjaan Umum. Hasil analisis diperoleh bahwa kinerja konsultan pengawas kurang optimal dalam hal pengendalian mutu dikarenakan konsultan pengawas tidak mengikuti acuan atau metode sesuai dengan peraturan yang ada. Faktor kurang optimalnya kinerja konsultan dipengaruhi berbagai macam faktor seperti kurangnya tenaga kerja, cuaca yang kurang mendukung sehingga tidak dapat dilakukan lembur sampai malam hari dan penyediaan bahan-bahan material mengalami keterlamabatan.
\end{abstract}

Kata Kunci : Pengendalian Mutu Proyek, Peranan Konsultan Pengawas, Penjaminan Mutu (Quality Assurance / QA), Pekerjaan Konstruksi 


\section{PENDAHULUAN}

Pembangunan merupakan salah satu tolok ukur perkembangan suatu daerah. Dalam pelaksanaan pembangunan suatu proyek di Indonesia khususnya di Kabupaten Nganjuk yang saat ini cukup berkembang, maka dibutuhkan suatu pengendalian mutu dan kerja sama antara berbagai pihak agar proyek yang di kerjakan dapat berjalan dengan baik sesuai dengan perencanaan[1][2][3]. Konsultan pengawas adalah pihak yang ditunjuk oleh pemilik proyek merupakan salah satu pihak yang berperan dalam mengendalikan mutu dari suatu pekerjaan konstruksi [4][5]. Pihak inilah yang salah satunya mempunyai tanggung jawab sebagai pengawas dan pengendali mutu atas setiap proses-proses kerja dalam pelaksanaan proyek konstruksi sehingga pekerjaan dapat diselesaikan sesuai dengan waktu pelaksanaan tanpa mengesampingkan mutu pekerjaan, [6][7][8].

Pada Tahun Anggaran 2017 Pemerintah Kabupaten Nganjuk mempunyai beberapa program pembangunan. Salah satunya adalah pembangunan dibidang pariwisata. Perkembangan pariwisata di Indonesia sekarang ini semakin pesat terutama di Kabupaten Nganjuk. Karena pengendalian mutu dalam pekerjaan konstruksi merupakan salah satu faktor yang penting dalam pekerjaan konstruksi maka penulis merasa perlu mengangkat tugas akhir dengan judul "Evaluasi Pengendalian Mutu Pada Proyek Pembangunan Obyek Wisata Sedudo Di Kabupaten Nganjuk".

Baik dan buruknya pekerjaan konstrkusi tidak terlepas dari kinerja konsultan pengawas dalam mengawasi dan mengendalikan pelaksanaan pekerjaan konstruksi [9][10][11]. Konsultan pengawas harus mampu mengendalikan pelaksanaan pekerjaan konstruksi sehingga pekerjaan sesuai dengan perencanaan, dapat diselesaikan tepat waktu dan mutu pekerjaan yang baik[12][13][14]. Adapun tujuan dari penelitian ini adalah untuk mengetahui dan mengevaluasi kinerja dan peranan konsultan pengawas dalam pengendalian mutu pada pekerjaan konstruksi berdasarkan dari hasil analisia laporan mingguan dan bulanan yang dilaporkan oleh konsultan pengawas kepada Pejabat Pembuat Komitmen[15][16][16].

\section{METODOLOGI PENELITIAN}

\subsection{Pengertian Manajemen Proyek}

Manajemen proyek berasal dari kata manajemen dan proyek. Manajemen proyek dapat diartikan sebagai proses manajemen yang meliputi perencanaan, pengorganisasian, pengawasan, pengarahan, serta pengendalian akan kekuatan atau kemampuan perusahaan yang digunakan dalam meraih tujuan organisasi/perusahaan yang telah ditentukan[17][18]. 


\subsection{Perencanaan Mutu}

Perencanaan mutu merupakan proses mengidentifikasi standar kualitas yang relevan, yang sesuai dengan kebutuhan pemilik dan memenuhi standar peraturan yang berlaku untuk setiap bagian pekerjaan, penetapan standar spesifikasi yang diberlakukan dalam proyek dan perencanaan strategi pencapaian standar yang direncanakan, [19][20].

\subsection{Pengendalian Mutu}

Pengertian Pengendalian mutu atau QC (Quality Control) adalah suatu proses peninjau kualitas dari semua faktor yang terlibat dalam kegiatan konstruksi, [4][21].

\subsection{Metode Pengendalian Mutu}

Metode yang digunakan untuk mengendalikan mutu suatu proyek dapat disesuaikan dengan jenis proyek dan kualitas yang di harapkan [22][23]. Secara umum, ada 3 metode yang sering dipakai dalam pengendalian mutu suatu proyek yaitu:

a) Pemeriksaan dan Pengkajian

b) Inspeksi dan Pemeriksaan Peralatan

c) Melakukan Pengujian Dengan Sampling

\subsection{Penjaminan Mutu (Quality Assurance / QA)}

Pengertian Penjaminan mutu atau QA (Quality Assurance) merupakan semua kegiatan atau pekerjaan yang dilakukan oleh organisasi proyek baik itu Pejabat Pembuat Komitmen, pelaksana pekerjaan atau kontraktor, pengawas pekerjaan untuk memberikan jaminan tentang kebijakan kualitas pekerjaan, tujuan dan tanggungjawab dari pelaksanaan pekerjaan agar hasil dari pekerjaan konstruksi dapat memenuhi kebutuhan dan kualitas dai pekerjaan yang direncanakan[4][24][25].

\subsection{Pengambilan Data}

Jenis penelitian dalam tugas akhir ini adalah jenis penelitian kualitatif yaitu data yang diambil dan digunakan dalam penelitian ini merupakan data sekunder dan berupa Laporan mingguan dan bulanan yang dilaporkan oleh CV. Pamoar Consultant selaku konsultan pengawas dalam Proyek Pembangunan Obyek Wisata Sedudo di Kabupaten Nganjuk. Teknik analisa data yang digunakan oleh penulis dalam penelitian ini adalah teknik komparasi dan implementasi. 


\section{ANALISA DAN PEMBAHASAN}

Dari perbandingan Laporan harian, mingguan, dan bulanan Konsultan Pengawas dengan Modul 5 Tata Cara Hasil Pengawasan Bangunan Gedung Kementerian Pekerjaan Umum dapat diketahui sebagai berikut:

Tabel 1. Daftar Ceklis Pelaporan Konsultan Pengawas

\begin{tabular}{|c|c|c|c|}
\hline No & Bagian Sistematika Pelaporan & Ada & $\begin{array}{c}\text { Tidak } \\
\text { Ada } \\
\end{array}$ \\
\hline 1 & Laporan Harian & & $\mathbf{v}$ \\
\hline 2 & $\begin{array}{l}\text { Laporan Mingguan: } \\
\text { Laporan Umum } \\
\text { Laporan Kemajuan Pekerjaan } \\
\text { Laporan Grafik Kemajuan Pekerjaan } \\
\text { Laporan Pengamatan Jumlah Tenaga Kerja } \\
\text { Laporan Pemasukan Bahan/ Material } \\
\text { Laporan Penggunaan Alat } \\
\text { Laporan Pengamatan Cuaca } \\
\text { Laporan Risalah Rapat } \\
\text { Laporan Daftar Hadir }\end{array}$ & $\begin{array}{l}\boldsymbol{v} \\
\boldsymbol{v}\end{array}$ & $\begin{array}{l}\boldsymbol{v} \\
\boldsymbol{v} \\
\boldsymbol{v} \\
\boldsymbol{v} \\
\boldsymbol{v} \\
\boldsymbol{v} \\
\boldsymbol{v}\end{array}$ \\
\hline 3 & \begin{tabular}{ll}
\multicolumn{2}{l}{ Laporan Bulanan: } \\
$-\quad$ Laporan Umum \\
- & Laporan Visual \\
- & Laporan Kemajuan Pekerjaan \\
- & Laporan Progres Kumulatif \\
- & Laporan Grafik Kemajuan Pekerjaan \\
- & Laporan Keuangan \\
- & Laporan Surat Menyurat \\
- & Laporan Risalah Rapat Lapangam \\
- & Laporan Daftar Hadir Rapat \\
- & Laporan Jumlah Tenaga Kerja \\
- & Laporan Pemasukan Bahan/ Material \\
- & Laporan Penggunaan Alat \\
- & Laporan Pengamatan Cuaca \\
- & Laporan Pengamatan Waktu Pelaksanaan
\end{tabular} & $\begin{array}{l}\boldsymbol{V} \\
\boldsymbol{V} \\
\boldsymbol{V}\end{array}$ & $\begin{array}{l}\mathbf{v} \\
\mathbf{v} \\
\mathbf{v} \\
\mathbf{v} \\
\mathbf{v} \\
\mathbf{v} \\
\mathbf{v} \\
\mathbf{v} \\
\mathbf{v}\end{array}$ \\
\hline
\end{tabular}




\begin{tabular}{|c|c|c|c|}
\hline No & Bagian Sistematika Pelaporan & Ada & $\begin{array}{c}\text { Tidak } \\
\text { Ada }\end{array}$ \\
\hline 4 & $\begin{array}{l}\text { Laporan Insidentil: } \\
\text { - } \quad \text { Laporan Hasil Pemeriksaan Mutu Gambar } \\
\text { rancangan } \\
\text { - } \quad \text { Laporan Hasil Pemeriksaan Mutu RKS } \\
\text { - } \quad \text { Laporan Hasil Pemeriksaan Perhitungan } \\
\text { - } \quad \text { Laporan Hasil Pemeriksaan Mutu Bahan } \\
\text { - } \quad \text { Laporan Hasil Pemeriksaan Pekerjaan } \\
\text { Sementara } \\
\text { - } \quad \text { Laporan Hasil Pemeriksaan Pekerjaan Akhir }\end{array}$ & & $\begin{array}{l}\mathbf{v} \\
\mathbf{v} \\
\mathbf{v} \\
\mathbf{v} \\
\mathbf{v} \\
\mathbf{v}\end{array}$ \\
\hline & $\begin{array}{l}\text { Data Pendukung } \\
\text { - } \quad \text { Usulan Sub Kontraktor } \\
\text { - } \quad \text { Persetujuan Pelaksanaan Pekerjaan } \\
\text { - } \quad \text { Memo Lapangan } \\
\text { - } \quad \text { Permohonan Ijin Pengecoran Beton } \\
\text { - } \quad \text { Uji Coba Hasil Pekerjaan }\end{array}$ & & $\begin{array}{l}\boldsymbol{v} \\
\boldsymbol{v} \\
\boldsymbol{v} \\
\boldsymbol{v} \\
\boldsymbol{v}\end{array}$ \\
\hline
\end{tabular}

Sumber: Laporan Konsultan Pengawas CV. Pamoar Consultant

Dari data-data diatas dapat di analisis bahwa tugas Konsultan Pengawas pada Proyek Pembangunan Obyek Wisata Sedudo Di Kabupaten Nganjuk hanya mengevaluasi dan melaporkan kemajuan pekerjaan setiap periode satu minggu dan setiap periode satu bulan. Konsultan pengawas tidak melakukan beberapa hal penting sebagai berikut:

A. Monitoring terhadap jumlah tenaga kerja yang berada dilokasi proyek.

Jumlah tenaga kerja sangat berpegaruh terhadap keberhasilan suatu pekerjaan pada proyek konstruksi. Produktivitas setiap tenaga kerja dipengaruhi oleh faktorfaktor yang berlainan yang dimiliki oleh masing-masing orang. Penempatan tenaga kerja sesuai dengan kemampuan juga sangat berpengaruh terhadap keberhasilan suatu proyek.

\section{B. Monitoring cuaca}

Daerah obyek wisata Sedudo merupakan kawasan dataran tinggi sehingga curah hujan sangat sering terjadi, hal ini mengakibatkan pekerja tidak dapat melakukan 
lembur sampai malam hari. Selain itu kondisi tanah yang licin membuat pekerja harus lebih berhati-hati.

C. Pengawasan terhadap bahan yang digunakan.

Beberapa pekerjaan telah dimulai sebelum request pekerjaan dibuat oleh kontraktor dan persetujuan material dari pengawas pekerjaan dikeluarkan. Hal ini sering terjadi karena pengawas pekerjaan dan direksi lapangan tidak selalu ada dilokasi pekerjaan, sementara pekerjaan harus segera dilakukan karena kondisi geografis lokasi yang memerlukan penanganan cepat. Sering sekali pengajuan ijin pekerjaan maupun ijin penggunaan material dilakukan hanya secara lisan tanpa dibuat berita acara. Hal ini menunjukkan bahwa kurangnya pemahaman dan komitmen antara pelaku pekerjaan konstruksi dalam melaksanakan kegiatan konstruksi. Pengajuan ijin pekerjaan dan ijin penggunaan material seharusnya dilakukan sebelum pekerjaan tersebut dilakukan. Sehingga tahapan pekerjaan dan material yang digunakan dapat dikendalikan oleh pengawas pekerjaan.

Pengajuan ijin pekerjaan dilengkapi dengan gambar pelaksanaan, metode kerja, jumlah tenaga kerja, jenis material yang akan digunakan, jenis peralatan yang akan digunakan, kondisi lokasi kerja dan volume pekerjaan. Gambar pelaksanaan dan metode kerja yang diajukan dalam request work harus sesuai dengan kondisi lokasi pekerjaan saat itu dan apabila terdapat perbedaan maka metode kerja dan gambar kerja harus diperbaharui terlebih dahulu sebelum pekerjaan dilaksanakan dan dilakukan pengajuan ulang. Ijin pekerjaan dan ijin material yang digunakan yang diajukan oleh kontraktor dapat digunakan apabila telah medapatkan persetujuan dari konsultan pengawas dan direksi lapangan. Untuk mendapatkan hasil pekerjaan yang sesuai dengan rencana dan dapat dipertanggungjawabkan. Untuk mencapai tujuan tersebut maka diperlukan juga kegiatan pengawasan berkala yang meliputi pemilihan bahan pada saat material sebagian sudah didatangkan, pengujian berkala pada saat material sebagian sudah datang, cara pelaksanaan, perawatan dan pemeliharaan material tersebut. Penggunaan Form Request Work dan Form Material Approval harus dilakukan sebagai alat administratif mengontrol material yang digunakan sesuai dengan RKS dan pekerjaan yang dilakukan terkontrol

Dalam upaya yang dilakukan dalam pengendalian mutu pada Proyek Pembangunan Obyek Wisata Sedudo Di Kabupaten Nganjuk ini Konsultan Pengawas melakukan pemantauan pekerjaan secara terus menerus, menerapkan dokumen kontrak, spesifikasi teknis, gambar rencana dan gambar kerja. Dalam pengendalian mutu dokumen merupakan suatu keharusan sebagai alat untuk mengetahui apakah prosedur-prosedur yang sudah direncanakan sudah dilaksanakan. Salah satu dokumen yang digunakan adalah laporan. Pada pekerjaan ini laporan 
yang dibuat oleh konsultan pengawas tidak hanya merupakan sebuah alat pertanggungjawaban kepada Pejabat Pembuat Komitmen saja tetapi laporan ini juga digunakan sebagai kelengkapan syarat pembayaran. Laporan konsultan pengawas juga terdapat informasi-informasi penting dalam proyek, baik itu berupa temuan-temuan masalah atau kendala selama proses pengerjaan, serta hal-hal lain yang dapat digunakan sebagai dasar mengambil keputusan berikutnya.

Metode yang digunakan pengendalian mutu salah satunya adalah dengan Penjaminan Mutu/ QA. Dengan adanya penjaminan mutu untuk memastikan agar metode kerja, material yang digunakan, dan peralatan yang digunakan dalam pembangunan proyek sesuai dengan rencana kerja dan syarat atau standar dokumen lain. Hal ini dilakukan untuk mempermudah apabila kedepannya dilakukan proses sertifikasi layak fungsi dari suatu bangunan oleh Pihak lain. Dalam kasus ini upaya yang dapat dilakukan adalah dengan melakukan pelaporanpelaporan dan checklist yang secara berurutan sebagaimana terlampir

\section{KESIMPULAN DAN SARAN}

\subsection{Kesimpulan}

Berdasarkan dari hasil pembahasan yang dilakukan pada Proyek Pembangunan Obyek Wisata Sedudo Di Kabupaten Nganjuk dapat diambil kesimpulan bahwa:

1. Peranan konsultan pengawas dalam pengendalian mutu pada Proyek Pembangunan Obyek Wisata Sedudo Di Kabupaten Nganjuk kurang optimal yang mengakibatkan pekerjaan mengalami keterlambatan sebesar 6,4\%. Sesuai dengan Peraturan Menteri Pekerjaan Umum No. 07/PRT/M/2011 tentang Standar Dan Pedoman Pengadaan Pekerjaan Konstruksi Dan Jasa Konsultasi termasuk dalam kategori kontrak kritis.

2. Konsultan Pengawas pada Proyek Pembangunan Obyek Wisata Sedudo Di Kabupaten Nganjuk hanya mengevaluasi dan melaporkan kemajuan pekerjaan setiap periode satu minggu dan setiap periode satu bulan

3. Untuk mendapatkan hasil pekerjaan yang baik maka proyek harus menyiapkan pengendalian mutu. Salah satunya dengan program penjaminan mutu (QA ). Sama halnya dengan biaya dan jadwal ,maka pada penjaminan mutu diperlukan suatu program penjaminan mutu yang sistematis, lengkap dan jelas

\subsection{Saran}

Sebagai tindak lanjut dari hasil penelitian yang telah dilakukan maka dapat disampaikan saran-saran kepada beberapa pihak sebagai berikut:

1. Diperlukan suatu komitmen yang lebih tinggi lagi dari pihak pelaksana pekerjaan, konsultan pengawas dan Pejabat Pembuat Komitmen (PPK) dalam hal kepatuhan melaksanakan prosedur pengendalian mutu. 
2. Pada proses pemilihan konsultan pengawas harus lebih selektif yang dilakukan oleh Unit Layanan Pengadaan (ULP) maupun oleh Pejabat Pengadaan Barang Dan Jasa (PPBJ)

3. Wajib dilakukan evaluasi tentang mekanisme pembayaran terhadap kontraktor maupun konsultan pengawas terkait kewajiban-kewajiban kontraktor dalam menyelesaikan pekerjaan sesuai dengan kontrak

\section{UCAPAN TERIMAKASIH}

Dalam penyusunan artikel ini, penulis ucapkan terimakasih kepada dosen pembimbing dan Universitas Kadiri. Penulis berharap agar artikel ini dapat bermanfaat bagi pembaca.

\section{DAFTAR PUSTAKA}

[1] M. Ichsan, "STUDI KINERJA PERUSAHAAN KONSTRUKSI DALAM LINGKUP DINAS PEKERJAAN UMUM KOTA MAKASSAR DISUSUN,” 2015.

[2] Sularso and H. Tahara, "Pompa Dan Kompresor," p. 290, 2000.

[3] A. I. Candra et al., "PENGECEKAN KELAYAKAN BANGUNAN GEDUNG SMA NEGERI 1 KOTA KEDIRI YANG DIGUNAKAN UNTUK AKTIFITAS BELAJAR BELAJAR,” Ukarst J. Univ. Kadiri Ris. Tek. Sipil, vol. 2, no. 2, pp. 108-116, 2019.

[4] R. Rivelino and A. Soekiman, "Kajian Pengendalian Mutu Konstruksi Pada Pengawasan Pelaksanaan Pembangunan Jaringan Irigasi Studi Kasus: Pembangunan Jaringan Irigasi Di. Leuwigoong,” Konstruksia, vol. 8, no. 1, p. 1, 2017, doi: 10.24853/jk.8.1.1-16.

[5] M. Labombang and S. Qamaria, "Use of Material on The Management Works Embakment Pondo's River-Poboya," Infrastruktur, vol. 2, no. 2, pp. 84-95, 2012.

[6] M. Kanginan, Fisika Marthen Kanginan Kelas 11 1 /4. 2013.

[7] M. A. Salim, ANALISIS KEBUTUHAN DAN KETERSEDIAAN AIR BERSIH ( Studi Kasus Kecamatan Bekasi Utara ). 2019.

[8] F. Malagutti, R. Anholon, O. Novaski, and J. De Souza Pinto, "Analysis of the Relationship of Maturity and Quality Management in Projects," Bus. Manag. Res., vol. 4, no. 1, pp. 1-16, 2014, doi: 10.5430/bmr.v4n1p1.

[9] S. N. Indah, Analisis Risiko Manajemen Mutu dan Penyusunan Prosedur Pengendalian Mutu Pekerjaan Subkontraktor Pada Proyek Apartemen Gold Coast PIK Jakarta. 2017.

[10] A. I. Candra, "ANALISIS DAYA DUKUNG PONDASI STROUS PILE PADA PEMBANGUNAN GEDUNG MINI HOSPITAL UNIVERSITAS KADIRI Agata," Ukarst, vol. 1, no. 1, pp. 63-70, 2017. 
[11] D. Sudarsana, "Pengendalian Biaya Dan Jadual Terpadu Pada Proyek Konstruksi.," J. Ilm. Tek. Sipil, vol. 12, no. 2, pp. 74-83, 2008.

[12] M. O. Y. L. Kawet, F. Halim, and M. I. Jasin, "PENGEMBANGAN SISTEM PENYEDIAAN AIR BERSIH UNTUK ZONA PELAYANAN IPA PILOLODAA KOTA GORONTALO,” J. Sipil Statik Vol.1, vol. 1, no. 12, pp. 800-806, 2013.

[13] D. Kartikasari and N. Nafi'iyah, "ANALISIS PERENCANAAN SISTEM PENYEDIAAN AIR BERSIH DI DESA MOJOSARI KECAMATAN MANTUP," Rang Tek. J., vol. 2, no. 1, pp. 35-39, 2019.

[14] B. D. M. Amalia Intan Sari, "Perencanaan Peningkatan Sistem Distribusi Air Minum Sumber Mata Air Umbulan di Wilayah Pelayanan Offtake Waru Kabupaten Sidoarjo," J. Tek. Pomits, vol. 2, no. 1, pp. 10-13, 2013.

[15] juli soemirat Slamet, Kesehatan Lingkungan. 2007.

[16] S. Sholeh and N. A. Affandy, "Perencanaan Sistem Penyedia Air Bersih Ikk Karangbinangun,” J. CIVILA, vol. 2, no. 2, p. 5, 2017, doi: 10.30736/cvl.v2i2.79.

[17] W. I. Ervianto, Manajemen Proyek Konstruksi. 2002.

[18] “UU No 18 Tahun 1999 " Jasa Konstruksi ",” doi: 10.5860/choice.41-2927.14.

[19] I. N. Ahzan, "Evaluasi Rencana Manajemen Mutu Pada Proyek Pembangunan Jembatan Sungai Semanggi Kab.Maros," J. Chem. Inf. Model., vol. 53, no. 9, pp. 1689-1699, 2013, doi: 10.1017/CBO9781107415324.004.

[20] "Peraturan Menteri Pekerjaan Umum No 04/PRT/M/2009 'Sistem manajemen mutu (smm) departemen pekerjaan umum."”

[21] A. Kaprina, S. Winarto, and Y. C. SP, "ANALISA PRODUKTIFITAS ALAT BERAT PADA PROYEK PEMBANGUNAN GEDUNG FAKULTAS SYARIAH DAN ILMU HUKUM IAIN TULUNGANGUNG,” Jurmateks, vol. 1, no. 1, pp. 1-11, 2018.

[22] F. Febriantoro, Y. C. S. P, and A. R. A, "STUDY PERENCANAAN PONDASI TIANG PANCANG JEMBATAN SEMBAYAT BARU II KECAMATAN MANYAR, KABUPATEN GRESIK,” Jurmateks, vol. 1, no. 1, pp. 148-159, 2018.

[23] R. Hidayah, A. Ridwan, and Y. C. S. P, "ANALISA PERBANDINGAN MANAJEMEN WAKTU ANTARA PERENCANAAN DAN PELAKSANAAN," Jurmateks, vol. 1, no. 2, pp. 281-290, 2018.

[24] M. Al Asyari, Y. C. S. P, and S. Winarto, "ANALISA PLAT KONVENSIONAL DENGAN PLATE FLATES PADA GEDUNG BPN KOTAMADYA MALANG," Jurmateks, vol. 1, no. 2, pp. 259-269, 2018.

[25] M. A. Ronald Simanjuntak and S. Sinta Suawa, "Analisis Sistem Manajemen Mutu dan Pengaruhnya Dalam Meningkatkan Kinerja Operasional Bangunan Gedung Tinggi 
Perkantoran di Jakarta Pusat," J. Ilm. Media Eng., vol. 4, no. 2, pp. 92-102, 2014. 